\title{
Reflets
}

Revue ontaroise d'intervention sociale et communautaire

\section{Un programme de formation innovateur et peu coûteux maintenant accessible à tous les francophones de l'Ontario}

\section{Josée Bergeron}

Volume 1, numéro 2, automne 1995

La santé communautaire en Ontario français : défis et espoirs

URI : https://id.erudit.org/iderudit/026092ar

DOI : https://doi.org/10.7202/026092ar

Aller au sommaire du numéro

Éditeur(s)

Reflets : Revue ontaroise d'intervention sociale et communautaire

ISSN

1203-4576 (imprimé)

1712-8498 (numérique)

Découvrir la revue

Citer cet article

Bergeron, J. (1995). Un programme de formation innovateur et peu coûteux maintenant accessible à tous les francophones de l'Ontario. Reflets, 1(2),

243-245. https://doi.org/10.7202/026092ar

Tous droits réservés (C) Reflets : Revue ontaroise d'intervention sociale et communautaire, 1995
Ce document est protégé par la loi sur le droit d'auteur. L'utilisation des services d'Érudit (y compris la reproduction) est assujettie à sa politique d'utilisation que vous pouvez consulter en ligne.

https://apropos.erudit.org/fr/usagers/politique-dutilisation/ 


\section{Un programme de formation innovateur et peu coûteux maintenant accessible à tous les francophones de l'Ontario.}

\section{Joséé B ergeron}

C oordonnatrice du programme de formation

C oalition franco-ontarienne sur le logement, 0 ttawa

Au printemps 1992, la population franco- ontarienne assistait à la naissance de la C oalition franco-ontarienne sur le logement (CFO L) qui se donna comme mandat de contribuer à l'amélioration des conditions de logement pour la population francophone de l'O ntario. Les groupes consultés dansce secteur ont mispeu de temps à faire valoir leurs besoins en matière de formation. La CFOL a donc demandé l'appui financier des gouvernements et des fondations communautaires pour développer un programme de formation en français.

En 1994, l'organisme recevait des contributions financières de Boulot O ntario/Action communautaire, du ministère du Patrimoine canadien et de la Fondation franco-ontarienne pour développer un programme de formation. C e dernier a été conçu de façon à répondre aux besoins des sociétés de logement à but non lucratif (le personnel et les locataires), des membres de coopératives d'habitation, des locataires du marché privé mais aussi de tous les francophones impliqués dans le domaine communautaire. 


\section{L'Ontario français se dote d'une nouvelle approche de formation communautaire: l'auto-formation!}

$\mathrm{N}$ otre premier réflexe a été de vouloir offrir la formation à l'intérieur du format habituel, c'est-à- dire d'offrir sur place des ateliers de toutes sortes.

Premier constat: toutes les formatrices et formateurs francophones possédant les compétences nécessaires se trouvaient principalement concentrés dans une seule et même région, ce qui pouvait entraîner des coûts faramineux pour leurs déplacements.

D euxième constat: étant donné que la communauté francophone est dispersée un peu partout en province, que ses ressources financières sont très limitées et qu'il existe des besoins urgents et spécifiques de formation, nous devions envisager la création d'un nouveau concept de formation. L'innovation était donc au rendezvous! Le type d'outil développé par la cFo L est vraiment différent de ce qu'on a vu jusqu'ici dans le domaine de la formation.

Pour une première année, nous avons décidé d'offrir à la communauté trois trousses de formation qui permettraient aux groupes de se former principalement par eux-mêmes, mais en interaction avec une formatrice ou un formateur au téléphone. $N$ ous avons nommé ce concept de formation l'auto-formation!

C et outil de formation offre les particularités suivantes:

1. Chaque trousse inclut un vidéo produit en collaboration avec des étudiantes et étudiants de la C ité collégiale et animé par François Leblanc, un professionnel de la télévision francoontarienne. À des moments précis dans le vidéo, on invite le groupe à s'arrêter pour faire des exercices pratiques.

2. La trousse inclut également un guide d'exercices et un guide pour la participante ou le participant. 
3. Pendant la rencontre, une personne- ressource embauchée par la CFOL se joint au groupe par téléphone. Cette personneressource peut alors apporter des précisions sur le sujet et répondre aux questions du groupe.

4. Pour que tous les membres du groupe puissent interagir avec la personne-ressource, un téléphone avec haut-parleur est fourni avec la trousse.

5. La trousse est louée et non achetée. Le prix de location se situe entre 125 \$ et 200 \$ pour 1995-1996 et il est fixe, indépendamment du nombre de personnes participant au groupe.

6. L'approche est tellement flexible et abordable qu'il est possible, avec un petit groupe de personnes, de suivre un atelier dans son propre salon!

Dès l'automne 1995, trois trousses seront disponibles sur les sujets suivants:

- Le fonctionnement d'un conseil d'administration

- Les droits des locataires en 0 ntario

- La résolution de conflits et de problèmes.

La CFO L offre cet outil à l'ensemble de la communauté francophone de l'O ntario.

Pour avoir plusd'information sur le programme ou pour commander une trousse d'auto-formation, il suffit de me contacter au bureau de la Coalition franco-ontarienne sur le logement au (613) 747-0363 ou à l'adresse suivante: 240 B, chemin M ontréal, Vanier (0 ntario) K 1L 6C 6. 